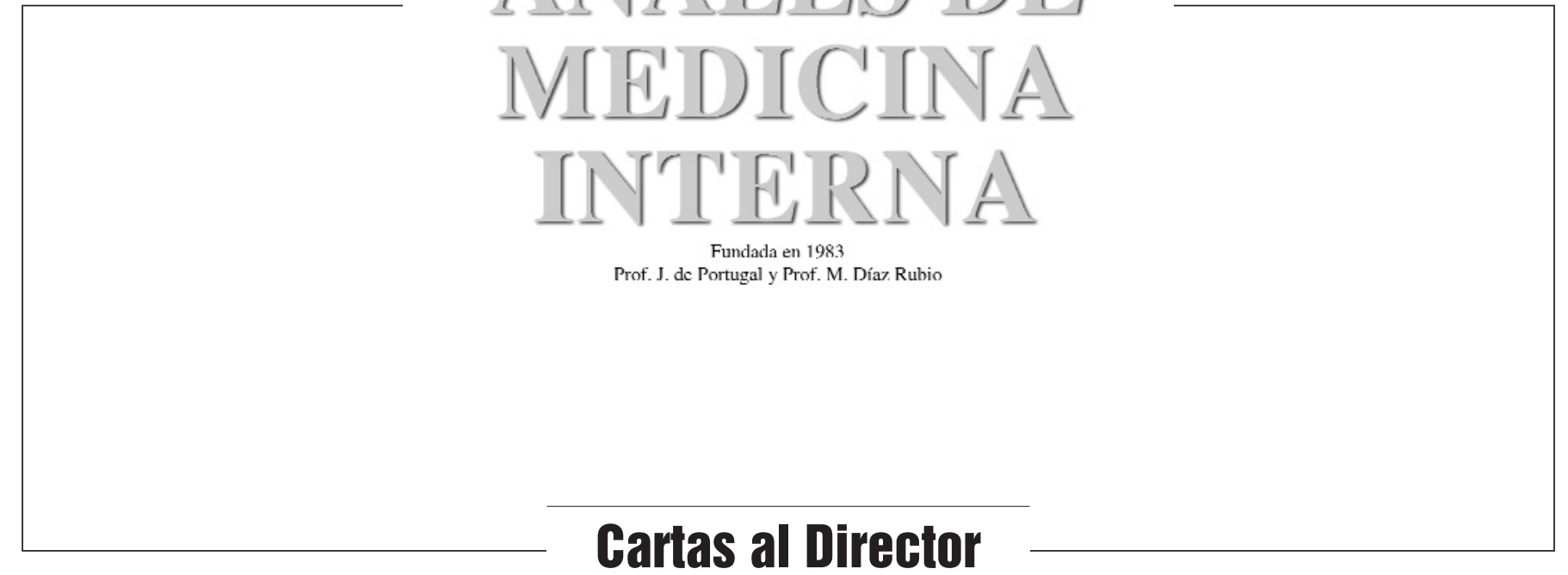

\section{Insuficiencia respiratoria tardía por restricción tras herniorrafia inguinal}

\section{Sr. Director:}

La cirugía abdominal superior se asocia con frecuencia con una significativa afectación de los mecanismos respiratorios, con mecanismos de defensa pulmonar y ventilatoria independientes de la anestesia general $(1,2)$. Además, es bien conocido el riesgo de complicaciones pulmonares tras la cirugía electiva abdominal (3). Sin embargo, la presencia de complicaciones pulmonares derivadas de la cirugía herniaria inguino-escrotal no es habitual, excepto en grandes hernias donde se produce insuficiencia respiratoria precoz por restricción, que con frecuencia impiden la extubación del paciente (4-7). La insuficiencia respiratoria tardía por restricción es infrecuente, aunque hay que sospecharla precozmente para evitar riesgos indeseables. Presentamos un paciente con una hernia inguino-escrotal gigante que durante el postoperatorio presentó un cuadro de insuficiencia respiratoria tardía por restricción.

Varón de 54 años sin antecedentes de interés que presenta desde hace 20 años tumoración inguinal derecha que progresivamente ha ido aumentando de tamaño hasta llegar a nivel de las rodillas. Valorado por su médico de cabecera es remitido a nuestra consulta para cirugía. A la exploración encontramos una gran hernia inguino - escrotal con pérdida de domicilio (Fig. 1). El paciente, a pesar de no tener problemas respiratorios, y dado el gran tamaño herniario, realizó ejercicios de fisioterapia durante los tres meses previos a la cirugía. Fue intervenido mediante anestesia general a través de una incisión inguino-escrotal derecha, hallando una gran hernia inguino-escrotal que contenía el intestino delgado casi en su totalidad, el colon derecho y la mitad del colon transverso, y todo el epiplon mayor. Se reintrodujo todo el contenido intestinal en la cavidad abdominal, y para evitar tensión se extirpó todo el epiplon mayor. El cierre de la pared abdominal se realizó con una prótesis de polipropileno según la técnica de Lichtenstein. El paciente comenzó con tolerancia oral a las 24 horas con normalidad. Sin embargo, a las 48 horas presentó disnea progresiva, inicialmente leve pero a las 12 horas era de reposo con taquipnea y taquicardia, precisando ingreso en UCI con el diagnóstico de insuficiencia respiratoria aguda secundaria a restricción. La gasometría arterial en ese momento fue de $\mathrm{pO}_{2}$
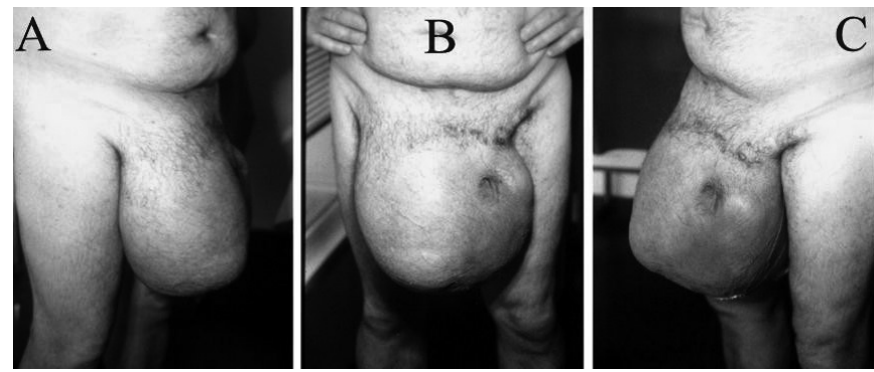

Fig. 1. Gran hernia inguino-escrotal vista en sus tres proyecciones (A. Lateral derecha; B. Anterior; C. Lateral izquierda).

de $39 \mathrm{mmHg}, \mathrm{pCO}_{2}$ de $66 \mathrm{mmHg}$ y $\mathrm{pH}$ de 7,30. La radiología de tórax mostraba un ascenso de los hemidiafragmas y un parénquima pulmonar poco aireado sin condensaciones. Inicialmente fue conectado a ventilación mecánica no invasiva, mejorando el intercambio gaseoso. Tras una evolución favorable se dió de alta a la planta de hospitalización tras 4 días en la UCI. Durante su estancia en planta se le realizó una espirometría que informó de alteración ventilatoria restrictiva severa. Tras doce días en planta, haciendo fisioterapia y con oxigenoterapia, el paciente fue dado de alta a su domicilio con oxigenoterapia domiciliaria. La evolución fue favorable y al mes se suspendió la oxigenoterapia. Actualmente, tras un año de la cirugía, el paciente está asintomático, y la hernia está corregida aunque al paciente le ha quedado un escroto redundante con contenido organizado y politabicado que está pendiente de extirpación.

Actualmente, con el nivel socio-económico de nuestro país, es infrecuente encontrarnos pacientes con hernia o eventraciones con pérdida de su derecho a domicilio, sobre todo si son pacientes jóvenes o de mediana edad sin factores de riesgo quirúrgicoanestésico como el caso que presentamos. En estos casos de hernias gigantes la realización de fisioterapia respiratoria preoperatoria es fundamental para evitar cuadros de insuficiencia respiratoria (8), aunque no siempre es suficiente, como ocurrió en nuestro paciente a pesar de la extirpación de todo el epiplon mayor. Esta situación puede agravarse si se presenta un ileo paralítico postoperatorio, pues aumenta la presión intraabdominal y por tanto la pulmonar. Cuando un paciente intervenido por una hernia con pérdida de domicilio presenta durante el postoperato- 
rio una insuficiencia respiratoria aguda grave, una maniobra que puede salvar su vida es la descompresión del abdomen provocando de nuevo la hernia o la eventración. En nuestro caso se valoró esta maniobra, pero ante su mejoría progresiva en UCI se desestimó la reintervención.

La cirugía en estos pacientes es peligrosa por el riesgo de insuficiencia respiratoria aguda postoperatoria dada la pérdida de domicilio en la cavidad abdominal del gran contenido herniario. Además, dicho riesgo no se limita a las primeras 24 horas, por ello estos pacientes deben vigilarse estrechamente durante el postoperatorio para detectar precozmente los cuadros de insuficiencia respiratoria aguda que puedan comprometer su vida, y se debe realizar fisioterapia postoperatoria para prevenirla $(8,9)$. Algunos autores han utilizado broncodilatadores para mejorar las disfunciones pulmonares tras cirugía de defectos de la pared abdominal en niños (10) lo cual podría ser aplicable perfectamente en casos de riesgo como el que acabamos de presentar.

\section{A. Ríos Zambudio, J. Sánchez Valero, L. Martín Díaz, M. del Pozo Rodríguez}

Servicio de Cirugía General y del Aparato Digestivo II. Hospital Universitario Virgen de la Arrixaca. Murcia

1. McKeague H, Cunningham AJ. Postoperative respiratory dysfunction: is the site of surgery crucial?. Br J Anaesth 1997; 79: 415-6.

2. Deodhar SD, Mohite JD, Shirahatti RG, Joshi S. Pulmonary complications of upper abdominal surgery. J Postgrad Med 1991; 37: 88-92.

3. Lawrence VA, Dhanda R. Risk of pulmonary complications after elective abdominal surgery. Chest 1996; 110: 744-50.

4. De Santis L, Frigo F, Bruttocao A, Terranova O. Pathophysiology of giant incisional hernias with loss of abdominal wall substance. Acta Biomed Ateneo Parmense 2003; 74 (Supl 2): 34-7.

5. Suter M, Martinet O. Postoperative pulmonary dysfunction after bilateral inguinal hernia repair: a prospective randomized study comparing the Stoppa procedure with laparoscopic total extraperitoneal repair (TEEP). Surg Laparosc Endosc Percutan Tech 2002; 12: 420-5.

6. Trivellini G, Bagni CM, Sollini A, Senni M, Leone S, Contessini Avesani E. Repair of giant hernias using more prosthesis. Hernia 2001; 5: 124-8.

7. Wantz GE. Giant prosthetic reinforcement of the visceral sac. The Stopa groin hernia repair. Surg Clin North Am 1998; 78: 1075-87.

8. Chuter TA, Weissman C, Starker PM, Gump FE. Effect of incentive spirometry on diaphragmatic function after surgery. Surgery 1989; 105: 488-93.

9. Stock MC, Downs JB, Gauer PK, Alster JM, Imrey PB. Prevention of postoperative pulmonary complications with CPAP, incentive spirometry, and conservative therapy. Chest 1985; 87: 151-7.

10. Nakayama DK, Mutich R, Motoyama EK. Pulmonary dysfunction after primary closure of an abdominal wall defect and its improvement with bronchodilators. Pediatr Pulmonol 1992; 12: 174-80.

\section{Pseudotumor cerebral en probable relación a ceftriaxona}

\section{Sr. Director:}

El pseudotumor cerebral (PC) es un síndrome complejo caracterizado por una alteración en la regulación de la presión intracraneal (PIC), con elevación de la misma, sin que exista lesión ocupante de espacio, hidrocefalia, trombosis de senos venosos cerebrales y anomalías bioquímicas o citológicas del LCR que lo justifique. Suele ser autolimitado y con frecuencia recidivante. Su morbilidad viene condicionada por la posible pérdida de visión, causada por la atrofia del nervio óptico (1) que puede producirse y que ha llevado a abandonar el calificativo de "benigna" que se utilizaba anteriormente.

Entre las múltiples causas que se asocian a la elevación de la PIC, se encuentran algunos fármacos, y dentro de éstos algunos antibióticos como las tetraciclinas, quinolonas o sulfametoxazol. Sin embargo, en una búsqueda bibliográfica en la base de datos MEDLINE (palabras clave: pseudotumor cerebri, cephalosporins, ceftriaxone) no hemos encontrado descrita la asociación entre PC y las cefalosporinas y por extensión con la ceftriaxona.

Presentamos el caso de un paciente tratado con ceftriaxona, asociado a gentamicina por presentar una endocarditis subaguda sobre válvula nativa, en cuya evolución aparecieron síntomas y signos compatibles con PC.

Se trata de un varón de 63 años, hábito asténico, fumador de 20-30 cigarrillos/día, y con antecedentes de hipoacusia en el oído izquierdo, tuberculosis pulmonar, prolapso de válvula mitral y de basalioma en la espalda intervenido.

El paciente fue remitido por presentar fiebre de hasta $39^{\circ} \mathrm{C}$ junto con lumbalgias y tiritonas de varias semanas de evolución, que mejoraban inicialmente con cefuroxima axetilo, pero que reaparecían tras suspender el tratamiento. Se inició el estudio ambulatoriamente indicando una analítica general, cuyos valores fueron normales, y una serie de hemocultivos (4) donde creció en todos $S$. viridans grupo $S$. mitis ( $S$. oralis) con sensibilidad intermedia a penicilina $\mathrm{G}$ y amoxicilina y sensible a ceftriaxona. Además, se realizó un TAC toraco-abdómino-pélvico y un enema opaco que fueron normales, un ecocardiograma transtorácico donde se observó una válvula mitral mixoide con prolapso de válvula posterior y una insuficiencia mitral moderada-severa con una dudosa imagen de verruga. Ante estos hallazgos, se diagnosticó al paciente de endocarditis subaguda y dada la estabilidad clínica que presentaba y el microorganismo aislado, se decidió iniciar tratamiento con ceftriaxona a dosis de $2 \mathrm{~g} /$ día (iv) asociado a gentamicina $300 \mathrm{mg}$ / día (iv) a cargo de la Unidad de Hospitalización a Domicilio. Al cumplir las dos semanas de tratamiento se suspendió la gentamicina manteniéndose las dosis de ceftriaxona. En ese momento, tanto los controles clínicos como los analíticos mostraban una buena evolución del cuadro infeccioso.

El día 21 de tratamiento antibiótico, el paciente refirió sensación de mareo, sin giro de objetos, e inestabilidad para la marcha, sin relación con la infusión del antibiótico. La exploración física general fue normal, apareciendo como único dato una discreta lateralización hacia la derecha al explorar la marcha. En los días posteriores, refirió mayor inestabilidad con aumento de la base de sustentación y sensación de visión borrosa, se solicitó una RNM craneal y una angioRNM de seno longitudinal que fueron normales y en la exploración oftalmológica se apreció un papiledema bilateral por lo que se decidió su ingreso en el Servicio de Neurología para valoración. En la nueva exploración neurológica destacó una marcha en tándem inestable con discreta adiadocinesia y papiledema bilateral. El resto de la exploración, pruebas analíticas y pruebas de imagen (Rx y RMN dorsolumbar) fueron normales. Tras dichas pruebas se realizó una punción lumbar, dando salida a un líquido claro, con unos recuentos celulares normales y cultivos negativos y con una presión de salida de $9 \mathrm{~cm}$. de agua. En el LCR se descartó la presencia de bandas oligoclonales, las pruebas serológicas para lúes y borreliosis fueron negativas, y el ECA y ADA fueron normales.

Ante el cuadro clínico, la buena evolución de la endocarditis y la casi finalización de las cuatro semanas de tratamiento se decidió suspender la ceftriaxona. En los días siguientes y sin tratamiento específico disminuyó el edema de papila y mejoró la visión y las alteraciones de la marcha, siendo el paciente dado de alta. A las dos semanas del alta, el paciente presentó diplopía con 
parálisis del VI par del ojo derecho y papiledema en ojo izquierdo, iniciándose tratamiento con corticoides y acetazolamida. Tras dos semanas de tratamiento desapareció completamente el edema de papila y la parálisis del VI par, manteniendo el paciente visión casi normal (cuadrantonopsia nasal inferior en ambos ojos en las pruebas campimétricas de control), mejorando objetivamente de su inestabilidad y trastornos de la marcha.

El PC fue descrito por Quinqué siendo los criterios diagnósticos actualmente establecidos: presencia de síntomas y signos de hipertensión intracraneal, de síntomas visuales o de ambos; presencia de papiledema; ausencia de síntomas y signos neurológicos focales y de alteración del nivel de conciencia (la paresia aislada de VI par no excluye el diagnóstico); ausencia de lesión cerebral en las pruebas de neuroimagen y LCR de composición normal y presión elevada (1).

El paciente presentado debutó con inestabilidad en la marcha y alteraciones visuales, síntomas relacionados con la hipertensión endocraneal, desarrolló un papiledema bilateral importante (hallazgo más característico de la exploración en estos casos) y una paresia del VI par no localizadora, situación que se describe entre un 14-35\% de los casos de PC (1). Las pruebas de imagen descartaron procesos expansivos endocraneales y las características del LCR fueron normales. Ciertamente la presión de salida del LCR obtenida fue normal, no teniendo determinaciones objetivas de hipertensión de LCR. El hecho de una determinación normal de PIC en el seno de un cuadro de hipertensión intracraneal es conocido, y por ello se aconseja repeticiones de la punción cuando el grado de sospecha de hipertensión intracraneal es alto (2) (actitud que no se tomó en el caso de nuestro paciente ante la buena respuesta al tratamiento).

Algunos autores (3) proponen que pueden existir pacientes susceptibles a niveles de PIC más bajos que otros y que pueden desarrollar este síndrome a presiones más bajas con buena respuesta al tratamiento estándar. Es más, en algunos casos, la paresia del VI par se relaciona con aumentos bruscos de la PIC (1). Con respecto a la causa que pudo motivar el síndrome, el paciente presentó como antecedente inmediato el diagnóstico de endocarditis. Hasta la fecha y salvo una descripción de PC en un paciente infectado con el VIH (4), no existen casos de PC en el seno de infecciones "per - se". El otro posible factor causal pudo ser el tratamiento antibiótico con ceftriaxona y aminoglicósidos. El ciclo con gentamicina se realizó completo apareciendo los primeros síntomas una semana tras su suspensión, estando el paciente en tratamiento con ceftriaxona (21 días), presentando una clara mejoría tanto en los síntomas como en la exploración (alteración de la marcha y papiledema) tras su suspensión, tal como se ha descrito $(5,6)$, en casos de hipertensión intracraneal secundaria a fármacos.

El pronóstico del síndrome es variable, presentando entre un $3-51 \%$ (1) de los casos una pérdida del campo visual de moderada a grave y que con un control y tratamiento precoz puede mejorarse. En el caso presentado el paciente mantenía una cuadrantonopsia nasal inferior en el control a los seis meses.

Se trata pues del caso de un paciente en tratamiento antibiótico parenteral con ceftriaxona, antibiótico ampliamente utilizado, que presentó una complicación, PC, no descrita hasta ahora en nuestro conocimiento, que puede causar una situación tan grave como una pérdida del campo visual y que por ello hay que considerar.

\section{A. Goenaga Sánchez, E. Sánchez Haya ${ }^{1}$, I. Martínez Soroa $^{2}$, M. Millet Sampedro, C. Garde Orbáiz}

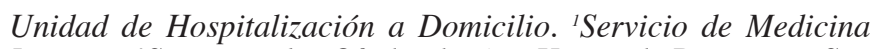
Interna. ${ }^{2}$ Servicio de Oftalmología. Hospital Donostia. San Sebastián
1. Santos S, López del Val LJ, Pascual LF, Mostacero E, Tejero C, Casadevall T, Morales F. Pseudotumor cerebral: análisis de nuestra casuística y revisión de la literatura. Rev Neurol 2001; 33: 1106-11.

2. Ecker A. Irregular fluctuation of elevated cerebrospinal fluid pressure. Arch Neurol Psychiatry 1955; 74: 641-9.

3. Green JP, Newman NJ, Store ZN, Nemerroff CB. "Normal pressure" pseudotumor cerebri. J Neuroophthamol 1997; 17: 241-16.

4. Traverso F, Stagnaro R, Fazio B. Benign intracraneal hypertension associated with HIV infection. Eur Neurol 1993; 33: 191-2.

5. Rosa N, Giamundo A, Jura A, Iaccarino G, Romano A. Mesalazine-associated benign intracraneal hipertensión in a patient with ulcerative colitis. Am J Ophthalmol 2003; 136: 212-3.

6. Chiu AM, Chuenkongkaew WL, Cornblath WT, Trobe JD, Digre KB, Dotan SA, Musson KH, Eggenberger ER. Minocycline treatment and pseudotumor cerebri syndrome. Am J Ophthalmol 1998; 126: 116-21.

\section{Carcinoma de células de Merkel}

\section{Sr. Director:}

El carcinoma de células de Merkel supone menos del 1\% de todos los tumores cutáneos malignos, lo que indica su gran rareza (1). Se denomina también carcinoma neuroendocrino cutáneo.

Se presenta con mayor frecuencia en las áreas expuestas al sol $(2,3)$. Recientemente hemos tenido ocasión de diagnosticar un nuevo caso y nos parece interesante presentarlo dada la escasa frecuencia de presentación de esta tumoración.

Varón de 73 años de edad, con antecedentes personales de hepatopatía crónica por el virus de la hepatitis C, hipertensión arterial y tuberculosis pulmonar hacía cincuenta años. Consultó al denotar una tumoración en el glúteo izquierdo de unos 4 meses de evolución, refería únicamente algunas molestias locales. No tenía fiebre ni pérdida de peso.

A la exploración existía una tumoración de 15 x 15 centímetros, semiblanda, fluctuante, algo enrojecida en el glúteo izquierdo. Se palpaba asimismo una masa compatible con adenopatías en la región inguinal izquierda. La auscultación cardíaca era normal y en la auscultación pulmonar existía una disminución del murmullo vesicular en el pulmón derecho. Abdomen: no se palpaban organomegalias.

Laboratorio: hemograma, hemostasia, bioquímica y CEA normales. Radiografía de tórax: paquipleuritis calcificada derecha. TAC abdominal: Tumoración de 16,5 x 14 x 11 centímetros que contacta con la musculatura glútea izquierda, sin descartar infiltración (Fig. 1). En la región inguinal izquierda hay una masa de 5,8 x 6,6 centímetros que sugiere adenopatías; hígado con granulomas calcificados.

Se realizó una biopsia quirúrgica, extirpándose un fragmento de $6 \times 7$ centímetros. El informe del servicio de Anatomía Patológica fue de tumor neuroendocrino cutáneo ( carcinoma de células de Merkel). Existía positividad para marcadores epiteliales: CK, CK20, EMA, Enolasa y MIB-1 y negatividad para marcadores mesenquimales: actina, vimentina, CD-68, CD-45, desmina, S-100, TTF1 y sinaptofisina. La biopsia fue remitida asimismo al servicio de Anatomía Patológica del Hospital Ramón y Cajal de Madrid, que confirmó el diagnóstico de nuestro centro. En dicho hospital se realizó resección de la tumoración y de las adenopatías inguinales, posteriormente se cubrió el defecto cutáneo mediante un colgajo con fascia lata, presentando en los siguientes días una necrosis parcial del colgajo y un episodio de retención aguda de orina. Fue remitido posteriormente nuevamente a nuestro centro.

Una TAC abdomino-pélvico mostró únicamente cambios degenerativos en ambas articulaciones sacro-iliacas. 


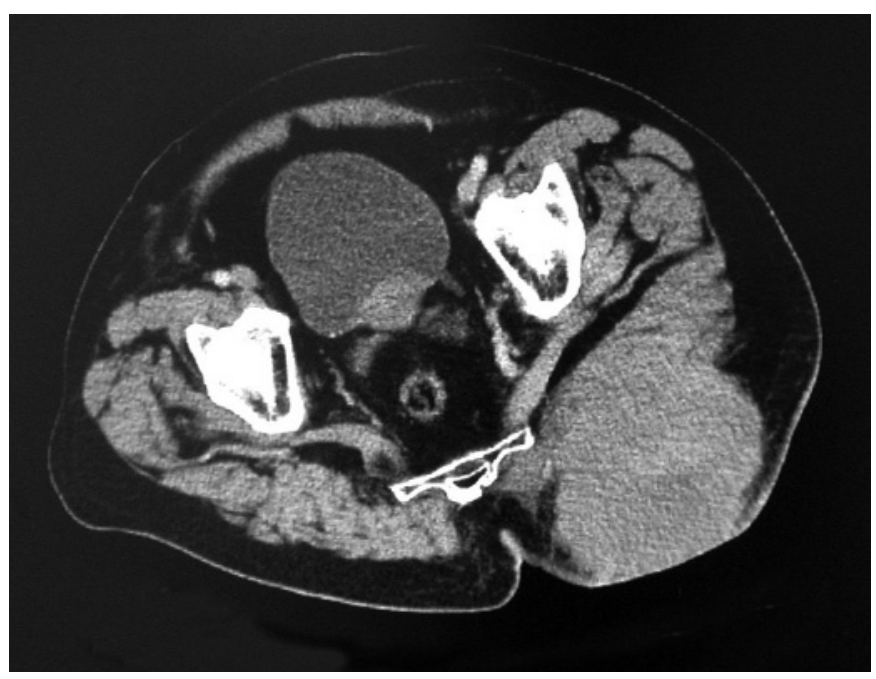

Fig. 1. Tumoración de $16,5 \times 14 \times 11$ centímetros que contacta con la musculatura glútea izquierda, sin descartar infiltración.

Se administró un ciclo de quimioterapia con el esquema cisplatino $\left(75 \mathrm{mg} / \mathrm{m}^{2}\right)$ y adriamicina $\left(40 \mathrm{mg} / \mathrm{m}^{2}\right)$. Posteriormente se volvió a abrir el colgajo cutáneo y se tuvo que interrumpir la quimioterapia, situación en la que nos encontramos en la actualidad. Han pasado 6 meses desde la cirugía y no han aparecido datos de recidiva tumoral.

Las lesiones del carcinoma de células de Merkel se localizan de modo predominante en la cabeza y el cuello $(50 \%)$, seguido de las extremidades (40\%), siendo mucho menos frecuente en el resto de las localizaciones, como es el caso que hemos presentado (2).

La afectación de los ganglios linfáticos regionales suele aparecer en cerca del $60 \%$ de los casos y suele presentarse en el transcurso de los primeros ocho meses de evolución de la tumoración $(2,3)$. La tercera parte de los enfermos desarrollarán metástasis a distancia durante la evolución del cáncer, siendo las localizaciones más frecuentes el hígado, hueso, pulmón, cerebro y piel $(2,3)$.

Se han definido 3 estadios para clasificar la enfermedad, según exista enfermedad cutánea únicamente, adenopatías locorregionales o metástasis a distancia. El patrón de células pequeñas o difuso, un elevado índice mitótico ( superior a 10 mitosis por campo), la existencia de invasión vascular o linfática o de metástasis a distancia, así como la posible coexistencia de estados de inmunodepresión implican claramente un peor pronóstico $(3,4)$.

Con respecto al tratamiento, la exéresis de la lesión primaria con unos márgenes de 2-3 centímetros es el manejo adecuado (5). La radioterapia debe recomendarse en los tumores de mal pronóstico, márgenes afectos, invasión vascular o linfática o irresecables (5). También se ha empleado quimioterapia con esquemas que incluyen doxorrubicina, ciclofosfamida y cisplatino; siendo la media de duración de la respuesta de unos 8 meses y la supervivencia media desde el inicio de la quimioterapia de nueve meses, lo que evidencia el mal pronóstico de esta tumoración (6).

\section{F. Marcos Sánchez, M. I. Albo Castaño, A. Viana Alonso, A. Zapata Ingelmo}

Servicios de Medicina Interna y de ${ }^{I}$ Anatomía Patológica. Hospital Nuestra Señora del Prado. Talavera de la Reina. Toledo
1. Chuan TY, Su WP, Muller SA. Incidence of cutaneous T cell lymphoma and other rare skin cancers in a defined population. J Am Acad Dermatol 1990; $23: 254-256$

2. Medina H, Urist MM, Piveash J, Heslin MJ, Bland KI, Benken SW. Multimodality treatment of Merkel Cell Carcinoma: Case series and literature review of 1024 cases. Am Surg Oncol 2001; 8: 204-208.

3. Gallard R, Weber R, Kosty MP, Greenway HT, Massullo V, Humberson C. Merkel Cell Carcinoma. Review of 22 cases with surgical pathologic and therapeutic considerations. Cancer 2000; 88: 1842-1850.

4. Lentz SR, Krewson S, Zutter M. Recurrent neuroendocrine( Merkel cell) carcinoma of the skin presenting as marrow failure in a man with systemic lupus erythematous. Med Ped Oncology 1993; 21: 137-141.

5. Savage P, Constela D, Disher C, Thomas JM, Gore ME. The natural history and management of Merkel Cell Carcinoma of skin: a review of 22 patients treated at the Royal Marsden Hospital. Clin Oncol 1997; 9: 164 167.

6. Voog E, Biron P, Martin JP, Blay JY. Chemotherapy for patients with locality advanced or metastatic Merkel Cell Carcinoma. Cancer 1999; 85: 2589-2595.

\section{Hemorragia digestiva de origen incierto}

\section{Sr. Director:}

La patología del intestino delgado ha sufrido una revolución desde la introducción de la cápsula endoscópica (CE) hace aproximadamente unos tres años. Dicha técnica ha permitido diagnosticar hemorragias gastrointestinales que previamente pasaban desapercibidas por las limitaciones del enteroscopio $(1,3,6)$.

La hemorragia digestiva de origen incierto es aquel sangrado digestivo la causa del cual no es aparente tras un estudio endoscópico convencional. Representa entre el 3-5\% de todas las causas de hemorragia gastrointestinal y es la principal indicación de la CE $(2,3)$.

A continuación presentamos el caso clínico de una paciente con hemorragia digestiva donde la gastroscopia y la colonoscopia fueron normales y que tras la $\mathrm{CE}$ se la diagnosticó de angiodisplasia yeyunal sangrante.

Mujer, de 72 años de edad, con antecedentes de alergia a penicilina, hipertensión arterial, hipertrigliceridemia, hiperuricemia, valvulopatía reumática con comisurotomía mitral en año 1973, portadora de prótesis biológica aórtica desde año 1985 y portadora de prótesis metálica mitral desde año 1994. Fibrilación auricular crónica. Hemorragia digestiva alta (HDA) en Febrero 2004 (se realizó colonoscopia hasta ciego que no mostró alteraciones de interés y en la gastroscopia se objetivó una imagen compatible con gastritis eritematosa inespecífica). Recibía tratamiento con furosemida, espironolactona, pantoprazol, acenocumarol, colchicina y alopurinol. Consultó en el servicio de urgencias por presentar, cuatro días previos al ingreso, deposiciones negras sin otros síntomas de interés, objetivándose en el momento de la exploración física, melenas. Ante la sospecha de HDA, se realizó gastroscopia que fue informada como resto bilioso en cámara gástrica, punteado blanquecino inespecífico en cúspide de pliegues de segunda porción duodenal y que no se biopsió por encontrarse la paciente anticoagulada y sin restos hemáticos. Días después se le practicó colonoscopia hasta ciego no consiguiéndose intubar el ileon terminal pero siendo informada como normal. El tránsito intestinal también fue normal.

Ante la normalidad de las pruebas diagnósticas anteriores y la evidencia clínica, se realizó la cápsula endoscópica por ser más accesible que la angiografía, visualizándose en el estudio una angiodisplasia en el yeyuno (Fig. 1) siendo ésta el origen de los 


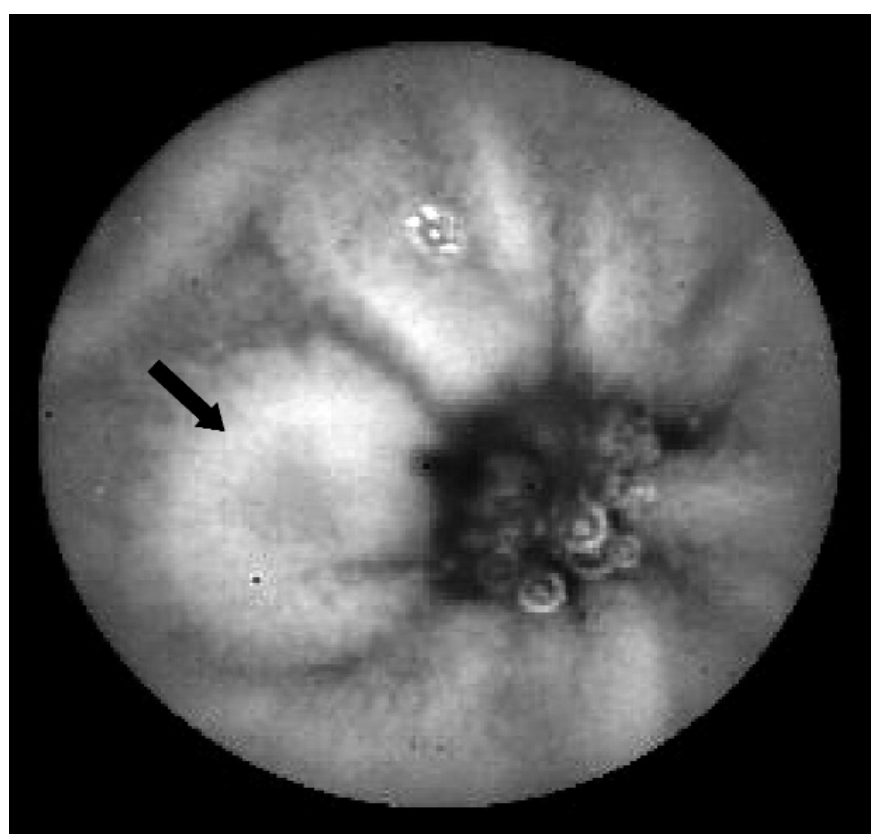

Fig. 1. Angiodisplasia yeyunal.

dos episodios de hemorragia digestiva que había presentado la paciente.

La angiodisplasia de intestino delgado era una causa poco valorada de hemorragia gastrointestinal antes de la introducción de la CE por la dificultad diagnóstica de la misma, pero que representa el $16 \%$ de todas las angiodisplasias del tracto digestivo (4).

La CE consiste en un dispositivo endoscópico de vídeo de un tamaño de 11 x $23 \mathrm{~mm}$ que es ingerido por el paciente, recorriendo todo el tubo digestivo por peristalsis y con una autonomía de unas siete horas. Durante ese tiempo recoge imágenes en color y posteriormente es expulsada de forma natural. Una grabadora situada en la cintura del paciente recibe las señales transmitidas por la cápsula a través de sensores conectados al abdomen. Dichas imágenes son procesadas por un sistema informático que las muestra en forma de película. La limitación del estudio en el momento actual es la imposibilidad de toma de biopsia y de actitudes terapéuticas $(2,5)$.

Las indicaciones actuales son la hemorragia digestiva de origen incierto y la sospecha de neoplasias y divertículos en el intestino delgado donde el estudio endoscócpico convencional es normal; se está estudiando su papel en la enfermedad inflamatoria intestinal. En el colon, de momento, no se ha demostrado la utilidad. La técnica está contraindicada en pacientes con datos de obstrucción intestinal, estenosis o fistulas, en el divertículo de Zencker, embarazadas y gastroparesia. Es una contraindicación relativa la presencia de marcapasos o desfibriladores (2).

En conclusión queremos resaltar la importancia de la introducción de esta nueva técnica que presenta una alta sensibilidad y especificidad para sangrados inciertos de origen gastrointestinal, con pocos efectos secundarios y que es fundamental para la detección de angiodisplasias de intestino delgado como causa de hemorragias digestivas que previamente pasaban desapercibidas (6).

P. J. Marchena Yglesias. C. López Aparicio. G. Arranz García, J. García-Cano Lizcano ${ }^{1}$, E. Redondo Cerezo ${ }^{1}$

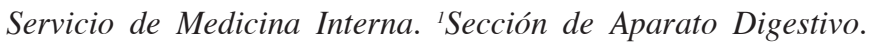
Hospital Virgen de la Luz. Cuenca
1. Couto G, Vieira A, Fonseca C, Velosa J, Moura MC. Angiodisplasia jejunal com hemorragia activa: diagnóstico por cápsula endoscópica. J Port Gastroenterol 2002; 9: 49-50.

2. Ali A, Santisi J, Vargo J. Video capsule endoscopy : a voyage beyond the end of the scope. Clev Clin J Med 2004; 71: 415-25.

3. Appleyard M, Gluckhovsky A, Swain P. Wireless capsule diagnostic endoscopy for recurrent small-bowel bleeding. N Engl J Med 2001; 344 : 232-3.

4. Niño J, Girón G, Sánchez P, Blanco R, Gómez LM, Muñoz JR. Hemorragia de tubo digestive secundaria a angiodisplasia yeyunal asociada a diverticulosis yeyunal. Rev Gastroenterol Mex 2000; 65: 81-4.

5. Rossini FP, Pennazio M. Small-bowel endoscopy. Endoscopy 2002; 34: 13-20.

6. Eli C, Remke S, Mary A, Helou L, Henrich R, Mayer G. The first prospective controlled trial comparing wireless capsule endoscopy with push enteroscopy in chronic gastrointestinal bleeding. Endoscopy 2002; 34: 355-9.

Síndrome general con ictericia, en varón de 59 años

\section{Sr. Director:}

El cáncer renal es un tumor poco frecuente, conocido por los internistas sobre la base de sus manifestaciones sistémicas. Previamente denominado por ello "tumor del internista". Actualmente por el incremento en la realización de técnicas de imagen su descubrimiento incidental se comienza a denominar "tumor del radiólogo". Es 2-3 veces más frecuente en hombres. La edad media al diagnóstico son 65 años. Se describe su asociación con factores que actúan de forma sinérgica, tanto ambientales como genéticos (tabaquismo, obesidad, hipertensión, enfermedad de Von Hippel-Lindau) (1).

Presentamos el caso de un varón de 59 años, con antecedentes de linfoma esplénico hace 26 años, con esplenectomia terapéutica, y cardiopatia isquémica. Ingresó en nuestro hospital, para estudio de síndrome general de un mes de evolución, con astenia, anorexia y pérdida de 4 kilogramos de peso. La exploración física era normal salvo por la presencia de hepatomegalia, e ictericia cutáneomucosa. En la analítica destacaba $\mathrm{Hb} 8,7 \mathrm{gr} / \mathrm{dL}$, VCM $76 \mathrm{fL}$, urea 58, creatinina 1,7 mg/dL, GPT 156, GOT 192, GGT 267, FA 1.368 $\mathrm{U} / \mathrm{l}$, y una bilirrubina total $5 \mathrm{mg} / \mathrm{dl}$, a expensas de la directa, el resto de la bioquímica que incluyó estudio de hipercoagulabilidad, virus hepatotropos y estudio de autoinmunidad fue normal. La radiografia de tórax era normal. La ecografia de abdomen, incluido Doppler, mostró hepatomegalia sin lesiones focales, ausencia del bazo, imágenes sugerentes de trombosis de la porta y de las venas hepáticas, y gran tumoración difusa en el riñón derecho. La tomografía axial computerizada (TAC) objetivó la presencia de un riñón derecho globalmente aumentado de tamaño, con contornos mal definidos y pérdida de la diferenciación córtico-medular a nivel de su tercio medio. La existencia de un amplio trombo que desde la desembocadura de la vena renal, asciende por la cava hasta cerca de la altura de la desembocadura de las venas suprahepáticas (Fig. 1), y la existencia de trombosis de las ramas portales principales. La RNM confirmó los hallazgos del TAC, que no alcanzaba la altura de las suprahepáticas ni se insinuaba en la aurícula. Se realizó PAAF con control ecográfico del riñón derecho, con el diagnóstico de carcinoma renal del sistema colector, o de Bellini, con extensión tumoral a la vena renal, cava inferior, porta y venas hepáticas, y síndrome de Budd-Chiari. Estadio III.

La extensión del carcinoma renal, con trombosis tumoral de las venas renal o cava inferior, está descrita entre un 4-10\% (2). 


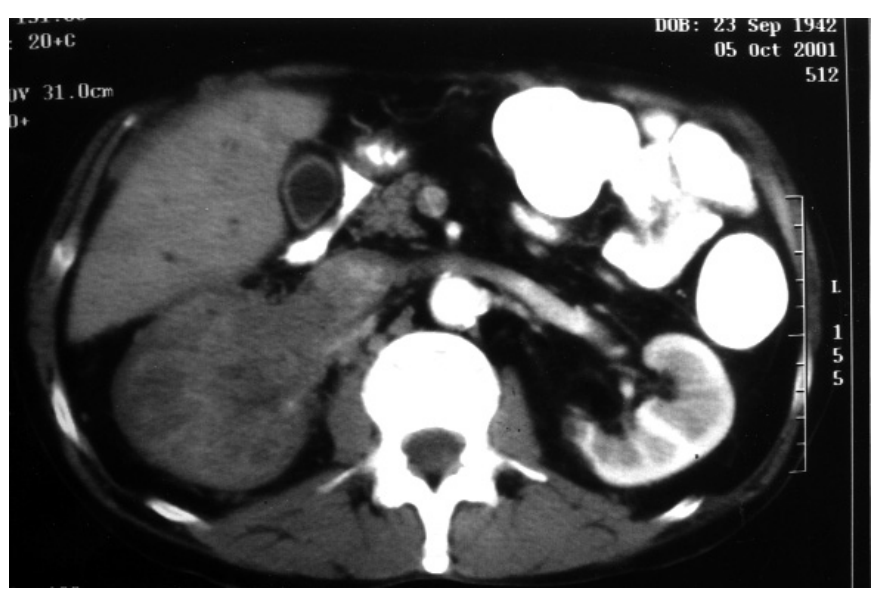

Fig. 1. TAC helicoidal de abdomen (fase venosa) a nivel del hilio hepático: trombosis de la vena porta principal y rama izquierda. Trombosis de la vena cava intrahepática.

La clínica no difiere de la forma habitual, ya que el trombo tumoral no es obstructivo o bien surgen colaterales suficientes (2). Unicamente en caso de desarrollar síndrome de Budd-Chiari, presentan hepatomegalia, dolor en hipocondrio derecho, ascitis e ictericia de forma lenta y progresiva, o bien desarrollan un cuadro de fallo hepático fulminante. Las técnicas de imagen son fundamentales tanto para el diagnóstico, como para delimitar la afectación vascular, con vistas a planear el tratamiento quirúrgico. La urografía intravenosa da evidencia indirecta de trombosis tumoral al demostrar un riñón no funcionante. La ECO y el TAC son muy útiles y precisos para demostrar la existencia del trombo en la mayoría de los pacientes (2), pero sin duda la RNM es el método más sensible (3). Si afectación intrahepática o supradiafragmática es sugerida, la ecocardiografía mostrará su presencia y extensión, incluso en área intracardiaca. El tratamiento, dado que en la mayoría de los casos no se produce invasión directa de la pared del vaso, consiste en la exéresis del tumor, y tras incisión de la vena renal o cava inferior, extracción del trombo tumoral $(2,4-6)$. Su pronóstico es similar a los casos sin afectación vascular, excepto aquellos que presentan un síndrome de Budd-Chiari con fallo hepático instaurado que tienen mayor mortalidad (7).

\section{E. M. Fonseca Aizpuru, F. J. Nuño Mateo, J. Noval Menén- dez, Y. García Alonso ${ }^{1}$}

Servicio de Medicina Interna, ${ }^{1}$ Radiología. Hospital de Cabueñes. Gijón.

1. Vogelzang NJ, Stadler WM. Kidney cancer. Lancet 1998; 352: 1691-96.

2. Tongaonkar HB, Dandekar NP, Dalal AV,Kulkarni JN, Kamat MR. Renal cell carcinoma extending to the renal vein and inferior cava: results of surgical treatment and prognostic factors. J Surg Oncol 1995; 59: 94100 .

3. Semelka RC, Shoenut JP, Magro CM, Kroeker MA, MacMahon R, Greenberg HM. J Magn Reson Imaging 1993; 3: 597-602.

4. Ciancio G, Soloway M. Renal cell carcinoma invading the hepatic veins. Cancer 2001; 92: 1836-42.

5. Marshall VF, Middleton RG, Holswade GR, Goldsmith EI. Surgery for renal cell carcinoma in the vena cava. J Urol 1970; 104: 414-20.

6. Skinner DG, Pfister RF, Colvin R. Extension of renal cell carcinoma into the vena cava: the rationale for aggressive surgical treatment. J Urol 1972; 107: 711-6.

7. Kume H, Kameyama S, Kayusa Y, Tajima A, Kawabe K. Surgical treatment of renal cell carcinoma associated with Budd-Chiari syndrome: report of four cases and review of the literature. Eur J Surg Oncol 1999; 25: 71-5.
Espondilitis brucelósica: a propósito de un caso atípico

\section{Sr. Director:}

La brucelosis es una zoonosis de distribución mundial causada por bacterias del género Brucella, siendo B. Melitensis la especie responsable de la mayoría de casos (1). Aunque se ha podido erradicar en diferentes países, en España continúa siendo una enfermedad endémica con un elevado coste socio-económico (2). La afectación osteoarticular es la complicación focal más frecuente y la espondilitis una de las localizaciones más usuales (3). Afecta sobretodo a pacientes de mayor edad, se localiza preferentemente en la zona lumbar y es necesaria una elevada sospecha clínica para llegar al diagnóstico (4) que se realiza en la mayor parte de los pacientes simultáneamente o tras el diagnóstico reciente de la infección sistémica (5). Comunicamos una forma de presentación y localización inusual de espondilitis brucelósica.

Varón de 41 años que consultó por cervicalgia de 3 meses de evolución y pérdida de $6 \mathrm{~kg}$ de peso. Se había realizado RMN cervical de forma ambulatoria en la que se observaba una alteración de señal en soma de C2, C3 y C4 con una lesión infiltrativa

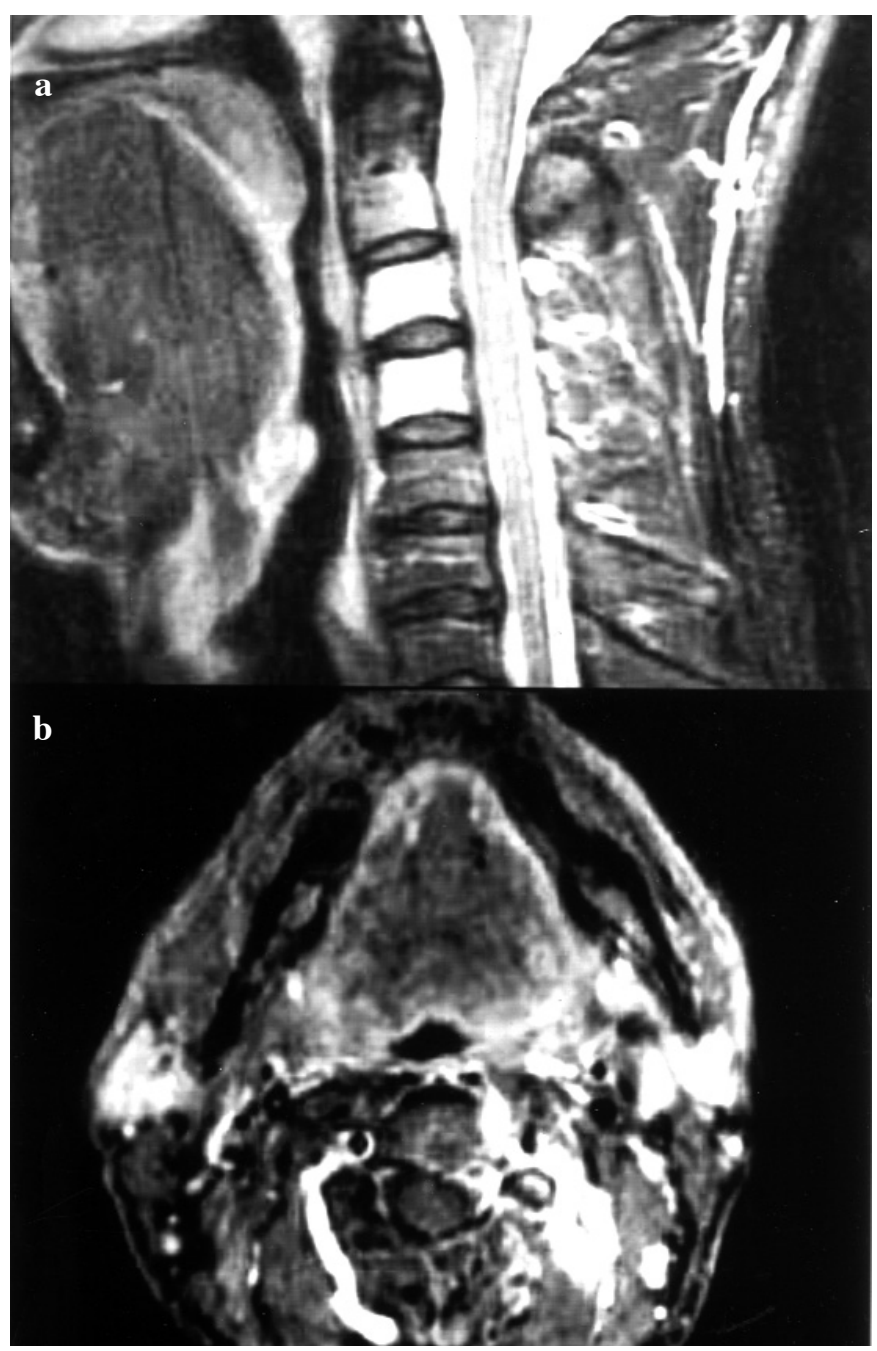

Fig. 1. a. Plano axial T1 con supresión grasa y contraste. Captación en tejido inflamatorio paravertebral, espacio epidural anterolateral izquierdo y en las paredes del absceso en musculatura paravertebral izquierda; b. Plano sagital STIR. Hiperintensidad por edema óseo en somas vertebrales C2-C4. Discos intervertebrales respetados. 
en C3 asociada a colección epidural y paravertebral izquierda (Fig. 1). Ingresó a estudio. No refería fiebre ni clínica sugestiva de proceso infeccioso acompañante. Era ganadero de ovejas. La exploración física del paciente no mostraba ninguna alteración salvo ligera molestia a la movilización del raquis cervical y una hepatomegalia de 3 traveses no dolorosa. De las pruebas de laboratorio destacar: leucocitos $9.200 \mathrm{cel} / \mathrm{mcl}$ (N 60\%), Hb $146 \mathrm{~g} / \mathrm{l}$, plaquetas $273.000 \mathrm{cel} / \mathrm{mcl}$, VSG $20 \mathrm{~mm} / \mathrm{h}$, PCR $0 \mathrm{mg} / \mathrm{l}$, creatinina $0,8 \mathrm{mg} / \mathrm{dl}$,GOT $15 \mathrm{UI} / 1$, GPT $12 \mathrm{UI} / 1$, GGT $20 \mathrm{UI} / 1$, bilirrubina $0,61 \mathrm{mg} / \mathrm{dl}, \mathrm{LDH}$ 281UI/l, CPK 48UI/l, fibrinógeno $364 \mathrm{mg} / \mathrm{dl}$, ferritina $120 \mathrm{ng} / \mathrm{ml}$ y los marcadores tumorales (CEA, alfafetoproteína, Ca 19,9 y PSA) estaban dentro de los límites de la normalidad. La radiografía de tórax y raquis cervical era normal. El test de Mantoux fue negativo, la técnica del rosa de Bengala positiva y el test de Coombs frente a anticuerpos anti-Brucella positivo a una dilución de 1: 640. No se obtuvieron crecimientos en los hemocultivos practicados. En la TC se objetivó una hepatomegalia homogénea y una colección a nivel de partes blandas paravertebral izquierda de $3 \mathrm{~cm}$ de diámetro. Se realizó PAAF ecodirigida de la masa paravertebral obteniéndose un material de aspecto purulento que se cultivó en medios para bacterias, hongos y micobacterias sin obtenerse crecimientos. En la citología se observaron células fusiformes sin rasgos de malignidad y material necrótico. Se inició tratamiento con doxiciclina $(100 \mathrm{mg} / 12$ h/oral/ 120 días) y gentamicina $240 \mathrm{mg} / \mathrm{im} /$ día durante los primeros 14 días. La evolución clínica ha sido satisfactoria. El paciente a los 8 meses de finalizar el tratamiento está asintomático, ha recuperado su peso habitual, y la RMN muestra una resolución completa del absceso epidural y de partes blandas quedando unos cambios inespecíficos de señal a nivel del soma de C3.

La brucelosis es una causa frecuente de espondilitis en nuestro país $(6,7)$ y sus manifestaciones clínicas, habitualmente, son dolor local, fiebre y síntomas constitucionales. La afectación de cuerpos vertebrales adyacentes suele asociarse a discitis, lo cual no se objetivó en nuestro paciente quien además no presentaba signos analíticos de inflamación. La localización cervical, aunque menos frecuente que la lumbar, es también posible y puede asociarse con afectación de partes blandas y absceso epidural $(8,9)$. En los últimos años, la RMN se ha convertido en una herramienta muy útil para el diagnóstico de estas lesiones (10) y es frecuente que al inicio del tratamiento haya una disociación entre la mejoría clínica y el aumento de las alteraciones objetivadas con la técnica de imagen. Por su mayor índice de fallos terapéuticos, se aconseja un tratamiento antibiótico que incluya aminoglucósidos y con una duración más prolongada que la brucelosis sin espondilitis asociada. El drenaje quirúrgico rara vez es necesario.

\section{Vallalta Morales, C. Morata Aldea, E. Solaz Moreno, P. Nogués ${ }^{1}$}

Servicios de Medicina Interna y Radiología. 'ERESA. Hospital Universitario La Fe. Valencia

1. Young EJ. An overview of human brucellosis. Clin Infect Dis 1995; 21: 283-9.

2. Ariza J. Brucellosis in the 21st Century. Med Clin (Barc) 2002; 119: $339-44$.

3. Colmenero JD, Reguera JM, Martos F, Sánchez-de-Mora D, Delgado M, Causse M, et al. Complications associated with Brucella melitensis infection: a study of 530 cases. Medicine (Balt) 1996; 75: 195-211.

4. Tekkok IH, Berker M, Ozcan OE, Ozgen T, Akalin E. Brucellosis of the spine. Neurosurgery 1993; 33: 838-44.

5. Solera J, Lozano E, Martínez-Alfaro E, Espinosa A, Castillejos ML, Abad L. Brucellar spondylitis: review of 35 cases and literature survey. Clin Infect Dis 1999; 29: 1440-9.

6. Calvo JM, Ramos JL, Garcia F, Bureo JC, Bureo P, Perez M. Pyogenic and non-pyogenic vertebral osteomyelitis: descriptive and comparative study of a series of 40 cases. Enferm Infecc Microbiol Clin 2000; 18: $452-6$.

7. Belzunegui J, Del Val N, Intxausti JJ, De Dios JR, Queiro R, Gonzalez $\mathrm{C}$, Rodriguez-Valverde V, Figueroa M. Vertebral osteomyelitis in northern Spain. Report of 62 cases. Clin Exp Rheumatol 1999; 17: 447-52.

8. Gonzalez-Gay MA, Garcia-Porrua C, Ibanez D, García-País MJ. Osteoarticular complications of brucellosis in an Atlantic area of Spain. J Rheumatol 1999; 26: 141-5.

9. Pina MA, Ara JR, Modrego PJ, Juyol MC, Capablo JL. Brucellar spinal epidural abscess. Eur J Neurol 1999; 6: 87-9.

10. Ozaksoy D, Yucesoy K, Yucesoy M, Kovanlikaya I, Yuce A, Naderi S. Brucellar spondylitis: MRI findings. Eur Spine J 2001; 10: 529-33.

\section{Varón de 65 años con lesión esternal}

\section{Sr. Director:}

Los dolores torácicos anteriores constituyen un motivo frecuente de consulta en la práctica clínica diaria, que nos obliga a hacer un amplio diagnóstico diferencial. Dentro de la pared torácica, los tumores que afectan al esternón son poco frecuentes. Existen pocos casos clínicos, y los datos disponibles proceden de series quirúrgicas o constituyen un hallazgo casual en necropsias. Pueden ser primarios, en su mayoría condrosarcomas, osteosarcomas, plasmocitomas y linfomas; o secundarios y constituir el primer signo de una neoplasia subyacente $(1,2)$. Se presenta un caso de adenocarcinoma de próstata que debutó con metástasis a nivel esternal.

Varón de 65 años de edad, con antecedentes de úlcera duodenal perforada intervenido hace 20 años. Ingresó en nuestro hospital para estudio de un dolor localizado a punta de dedo en región condroesternal, de 6 meses de evolución, que se había incrementado en intensidad y duración, le impedía conciliar el sueño y era rebelde a diferentes pautas de analgesia. Además refería nicturia de 2-3 micciones/noche desde hacia 4 meses. En el tacto rectal se objetivó una próstata elástica grado I/IV con nódulos en su superficie, el resto de la exploración física fue anodina. La analítica general era normal, a excepción de una fosfatasa alcalina (FA) de $165 \mathrm{U} / 1$ (normal hasta 117), antígeno carcinoembrionario (CEA) $3,8 \mathrm{ng} / \mathrm{ml}$ (normal hasta 3 ) y antígeno prostático (PSA) $27 \mathrm{ng} / \mathrm{ml}$ (normal hasta 4). La gammagrafía ósea con Tecnecio-99 mostró la existencia de hipercaptación en el esternón tanto en fase vascular como tardía, con un área hipocaptadora central. La tomografía axial computerizada (TAC), y resonancia magnética nuclear (RMN) mostraron una lesión lítica y expansiva en el cuerpo del esternón, con zonas sugerentes de rotura de la cortical (Fig. 1).

Se realizó PAAF de la lesión lítica esternal, y biopsia prostática del lóbulo derecho e izquierdo. Se obtuvo la misma celularidad neoplásica en ambas muestras, con el diagnóstico de adenocarcinoma de próstata poco diferenciado.

En un estudio retrospectivo de pacientes con tumores del esternón, dolor y tumefacción de la pared torácica secundario a neoplasia, en más del $90 \%$ la afectación esternal fue la manifestación inicial del tumor primario (3). Éste se localiza habitualmente a nivel del tiroides, riñón o mama, y en raras ocasiones en pulmón, cólon o hígado $(1,4,5)$. En el carcinoma de próstata las metástasis óseas en pelvis, pared torácica y columna son un hallazgo común, hasta en un $28 \%$ de casos según las series (6), sin embargo la afectación esternal constituye una forma de presentación y una localización casi anecdótica $(7,8)$. En general, las metástasis esternales se localizan a nivel del cuerpo respetando el apéndice xifoides. Clínicamente debutan con dolor o tumefacción, que aumenta progresivamente de tamaño. Pueden presentar 


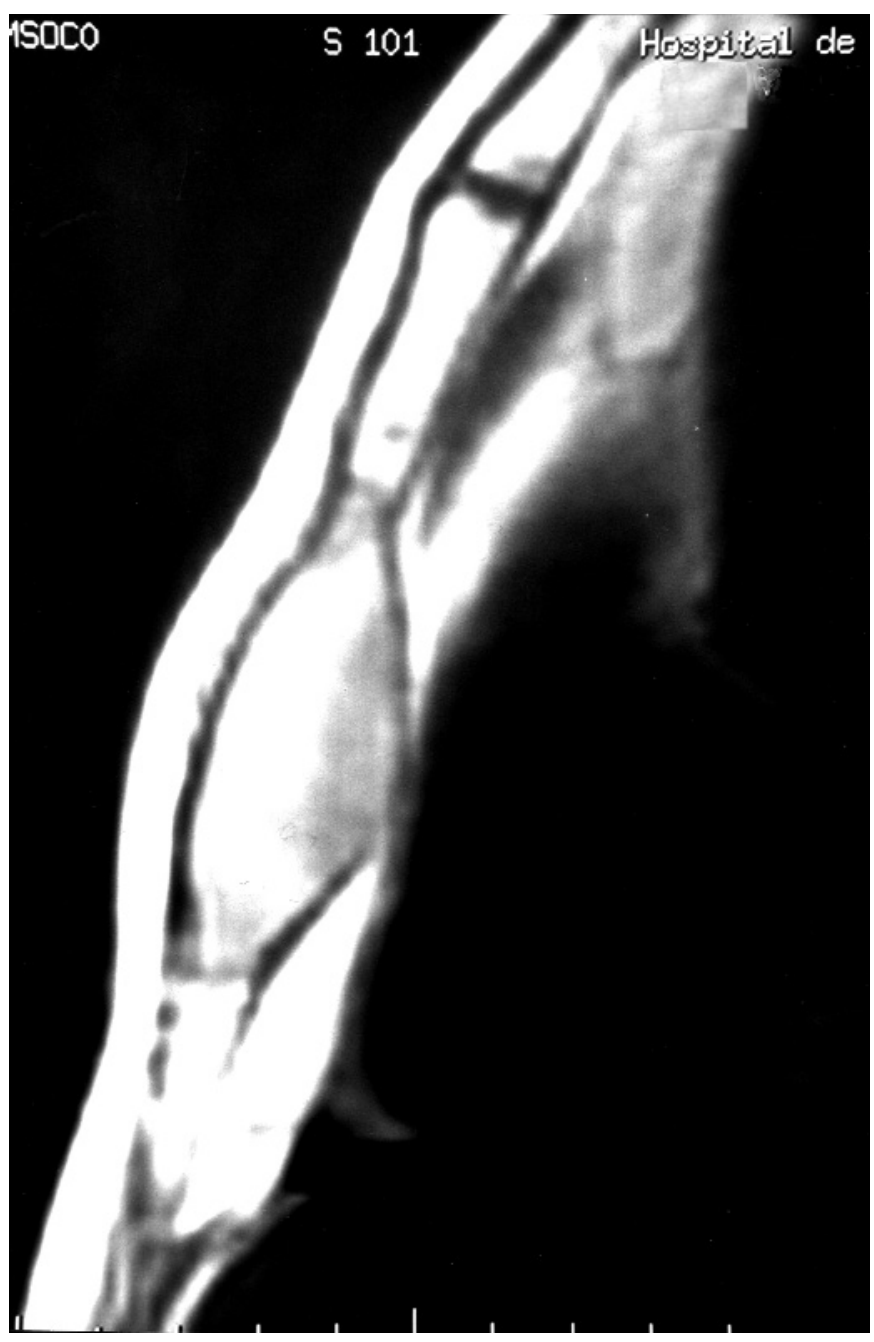

Fig. 1. RMN: Lesión lítica esternal con rotura de la cortical.

características pulsátiles, cuando se asocian a tumores renales o de tiroides (9). La gammagrafía ósea con Tc99 suele mostrar hipercaptación. La TAC y la RMN, revelan la existencia de lesiones líticas, el grado de extensión y su relación con estructuras vecinas. El diagnóstico de confirmación se basa en la punción aspiración con aguja fina (PAAF) o biopsia. El tratamiento y pronóstico es etiológico y se fundamenta en la histología del tumor primario. La resección de la lesión esternal, con posterior reconstrucción de la pared torácica, constituye una actitud terapeútica no exenta de controversia. Se han comunicado series con una supervivencia media de 24 meses (10).

\section{E. M. Fonseca Aizpuru, F. J. Nuño Mateo, M. J. Menéndez} Calderón, E. Segui Riesco

Servicio de Medicina Interna y ${ }^{I}$ Anatomía Patológica. Hospital de Cabueñes. Gijón

1. Downey RJ, Huvos AG, Martín N. Primary and secondary malignancies of the sternum. Semin Thorac Cardiovasc Surg 1999; 11: 293-296.

2. Poulton TB, O`Donovan PB. Sternal mass. Chest 1994;106:575-576.

3. Toussirot E, Gallinet E, Augé B, Voillat L, Wendling D. Pathologie tumorale maligne de la paroi thoracique antérieure. Rev Rhum 1998; 65: 397-405

4. Vasireddi SS, Lo Presti PA, Gorski L, Patel A, Bradnock H, Barot NV.
Resected sigmoid carcinoma with 13 year metastasis free survival. Sternal recurrence detected by immunoscintigraphy. J Clin Gastroenterol 1996; $23: 128-130$.

5. Garcia de Lucas MD, Jurado Gámez B, Pérez Sicilia M, Trujillo Santos AJ. Metástasis esternal por hepatocarcinoma. An Med Interna (Madrid) 2002; 19: 62-63.

6. Lobo G, Ladron de Guevara D, Salgado G, Donoso G, Bagus F. Bone scintigraphy in prostatic cancer. Correlation with clinical and laboratory features and with survival. Rev Med Chil 1999; 127: 181-188.

7. Strauss J, Tavernier C, Hirschhorn P, Aboudaram A. Les lesions lytiques du sternum. Sem Hop Paris 1987;63:3083-3088.

8. Grannis FW, Caffarati J, Dikranian H. Aortic valve replacement in the presence of sternal metastases from carcinoma: a case report. J Thorac Cardiovasc Surg 1987; 94: 635-636.

9. Estrera AS, Platt MR, Mills LJ, Shaw RR. Pulsatile sternal tumor: report of three cases and a review of the literature. Ann Thorac Surg 1981; 31: 244-250.

10. Carbognani P, Vagliasindi A, Costa P et al. Surgical treatment of primary and metastatic sternal tumours. J Cardiovasc Surg 2001; 42: 411414.

\section{Un caso de gastritis enfisematosa tratada con antibióticos con éxito}

\section{Sr. Director:}

La gastritis enfisematosa es una forma rara de gastritis flemonosa asociada a invasión de la pared gástrica por bacterias formadoras de gas. Pueden predisponer a la invasión bacteriana la lesión de la mucosa gástrica por alcoholismo, traumatismo, ulcera péptica o intervención gástrica. El tratamiento de elección son los antibióticos y la cirugía. Por la falta de síntomas típicos el diagnóstico se retrasa con frecuencia, lo que asociado con una rápida evolución a peritonitis resulta con frecuencia con un resultado letal.

Comunicamos un nuevo caso de gastritis enfisematosa de presentación atípica que se diagnosticó por el hallazgo de un engrosamiento de la pared gástrica y presencia de aire en su interior detectados en la tomografía computarizada (TC) abdominal que se resolvió con tratamiento antibiótico.

Varón de 71 años con astenia, anorexia y pérdida de $12 \mathrm{~kg}$ de 6 semanas de evolución, acompañado de dolor en epigastrio e hipocondrio izquierdo con náuseas y vómitos desde hacia una semana. Entre los antecedentes destacaban una lobectomía pulmonar izquierda por quiste hidatídico hacía 15 años y hemorragia por úlcus gástrico ocho años antes. En la exploración física el abdomen era doloroso a la palpación en epigastrio e hipocondrio izquierdo sin signos de irritación peritoneal. Permaneció afebril durante el periodo de estudio. En los análisis destacaba hemoglobina $11 \mathrm{~g} / \mathrm{dl}$, hematocrito $0,34 \mathrm{l} / \mathrm{l}$, VCM $84 \mathrm{fl}$, plaquetas $263 \mathrm{x}$ $10^{9} / 1$, leucocitos $4,6 \times 10^{9} / 1(66 \%$ N, $19 \%$ L, $10 \%$ M 5\% E), VSG 70. Los hemocultivos fueron negativos. En la Rx abdomen se observó una pérdida del luminograma gástrico normal sin otros hallazgos. En la TC abdominal se evidenció un engrosamiento de la pared gástrica de forma difusa, muy hipodensa, de morfología nodular con aire intramural en fundus (Fig. 1). En la gastroscopia se observó un exudado fibrinoso de bordes irregulares en cara posterior de cuerpo gástrico y antro, y en incisura angularis una úlcera de $1,5 \mathrm{~cm}$ de diámetro. Las muestras de biopsia resultaron diagnósticas de gastritis crónica atrófica con signos de actividad inflamatoria. Con el diagnóstico de gastritis flemonosa se instauró tratamiento con ceftriaxona y metronidazol. El paciente presentó resolución de los síntomas en pocos días y de las imágenes de TC en el control realizado a las tres semanas. Una nueva 


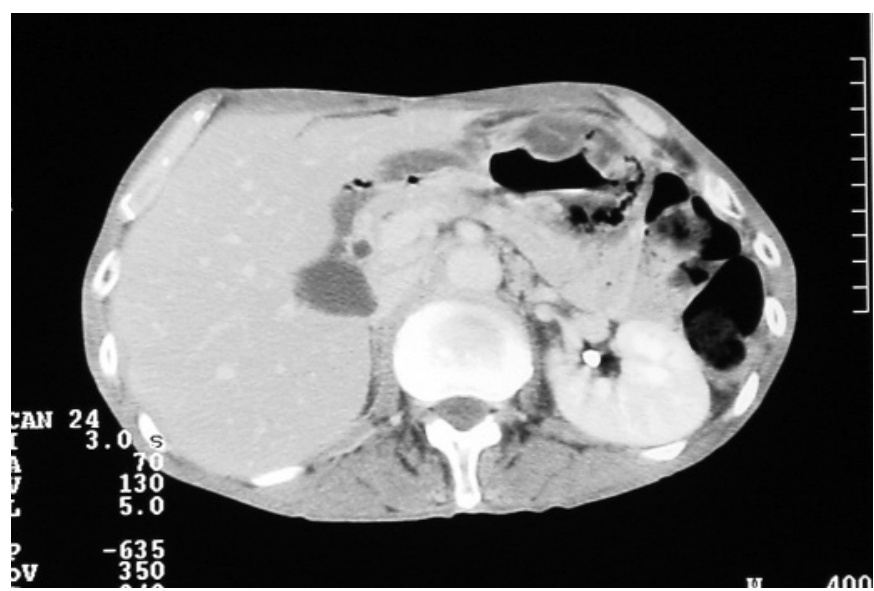

Fig. 1. TC donde se observa un engrosamiento de la pared gástrica de forma difusa, muy hipodensa, de morfología nodular con aire intramural en fundus.

gastroscopia a las 4 semanas mostró cicatriz de la úlcera gástrica con una mucosa irregular en cuerpo y antro sin ulceración ni fibrina. La biopsia mostró una gastritis crónica atrófica con discreta actividad inflamatoria. En el control realizado a los seis meses el paciente permanece asintomático.

La gastritis enfisematosa debe ser diferenciada de otras entidades con presencia de gas en la pared gástrica como el enfisema gástrico. Existen dos métodos por los que se acumula gas en la pared gástrica: por la penetración de gas en la pared gástrica desde la luz gástrica, el peritoneo o desde su unión con el esófago y duodeno (enfisema gástrico) o por la formación de gas en la pared gástrica (gastritis enfisematosa).

La patogenia de la enfermedad no está clara, pero se ha sugerido que un descenso de la acidez del medio (tratamiento antiulceroso) o la presencia de una lesión de la mucosa gástrica (úlcera, gastritis) podrían permitir la colonización bacteriana y la posterior progresión de la infección hacia planos profundos $(1,2)$. Otro mecanismo patogénico propuesto es la diseminación por vía hematógena a partir de un foco séptico a distancia. Los patógenos más frecuentes son estreptococos, Escherichia coli y Enterobacter sp, seguidos de Pseudomona aeruginosa y Clostridium perfringens. Los síntomas incluyen dolor abdominal, diarrea, náuseas, vómitos y fiebre. El inicio de los síntomas varían de pocas horas hasta 6 semanas, siendo más frecuente una evolución de pocos días. Son raras las formas tórpidas con ausencia de fiebre y de otros indicadores de infección aguda (2). El diagnóstico se realiza por radiología simple de abdomen y/o TC abdominal. Los hallazgos típicos de gastritis enfisematosa en la TC, además de la presencia de gas en la pared, incluyen el engrosamiento de la pared gástrica que pueden ayudar a diferenciar la gastritis enfisematosa del enfisema gástrico (3). El pronóstico es malo con una mortalidad del $60 \%$, y una morbilidad (contracturas gástricas) cercana al 21\% (1).

En la actualidad no se ha definido el tratamiento para lograr una mejor supervivencia (4); el tratamiento actual incluye los antibióticos y la cirugía si la situación del paciente lo permite, habiéndose descrito recientemente algún caso de tratamiento antibiótico con éxito $(5,6)$. El tratamiento antibiótico debe cubrir siempre bacterias Gram negativas y anaerobias aunque no se aíslen en cultivos ya que es posible su presencia intramural y sin que se aíslen en líquidos gástricos. Sin embargo la enfermedad es rara por lo que el diagnóstico clínico precoz no es fácil para un inicio rápido del tratamiento y así mejorar el pronóstico.

Este caso muestra un nuevo caso de gastritis enfisematosa de presentación atípica, en un paciente con ulcus gástrico como único factor predisponente y en el que el aumento de la presión intraluminal por los vómitos pudo tener un papel facilitador que se resolvió con tratamiento antibiótico empírico de amplio espectro.

\section{Gázquez, P. Vicente de Vera ${ }^{1}$, A. Sheik Elard, M. Martín Berra}

Servicios de Medicina Interna y ${ }^{I}$ Radiología. Hospital Universitario Arnau de Vilanova. Lleida

1. Moosvi AR, Saravolatz DL, Wong DH, Simms SM. Emphisematous gastritis: Case report and rewiew. Rev Infect Dis 1990; 12: 848-855.

2. Merino MT, Falguera M. Panadés MJ, Garcia M. Gastritis flemonosa en un paciente con úlcera gástrica crónica. Med Clin (Barc) 1997; 109: 2789.

3. de Lange EE, Slutsky VS, Swanson S, Shaffer HA Jr. Computed tomography of emphysematous gastritis. J Comp Assist Tomogr 1986; 10: $139-41$.

4. van Mook WN, van der Geest S, Goessens ML, Shoon EJ, Ramsay G. Gas within the wall of the stomach due to emphysematous gastriti; case report and review. Eur J Gastroenterol Hepatol 2002; 14: 1155-1160.

5. Iwakiri Y, Kabemura T, Yasuda D, Okabe H, Soejima A, Miyagahara T, Okadome K. A case of acute phlegmonous gastritis successfully treated with antibiotics. J Clin Gastroenterol 1990: 28; 175-177.

6. Hu DC, McGrath KM, Jowell PS, Killenberg PG. Phlegmonous gastritis: successful treatment with antibiotics and resolution documented by EUS Gastrointest Endosc 2000; 52: 793-795.

\section{La Medicina Interna: horizontes lejanos}

\section{Sr. Director:}

He leído el artículo "La Medicina Interna: situación actual y nuevos horizontes" (1), y su lectura, sin duda, me sugiere varias reflexiones que deseo expresar por escrito.

Comparto la casi totalidad de este análisis del médico-internista y, ante todo, el fondo de su mensaje, lleno de pasión por la medicina interna.

No obstante, deseo hacer algunos comentarios y puntualizaciones, tal vez de tono menor:

1. Cajal dio pasos de gigante en neurohistología y no en neurofisiología. Severo Ochoa escribió acerca de "los descubrimientos del gran neurohistólogo español”, y reconoce, además, que sólo hacia el final de la vida de Cajal algunos de sus más distinguidos discípulos (Castro, Lorente de No) se adentraron en el campo de la neurofisiología (2).

2. Aunque la Sociedad Española de Medicina Interna (SEMI) fue fundada en España en 1952, el término medicina interna se utiliza ya en 1919. En el primer Congreso Nacional de Medicina (3) está claramente separada la Sección de medicina interna de la cirugía. Intervinieron en él prestigiosos internistas (Novoa Santos, Marañón, Pittaluga, Bañuelos, etc.).

3. A pesar del indiscutible influjo del controvertido Letamendi (4), un médico y profesor cargado de sorprendentes polémicas que se prolongan desde hace más de un siglo, es difícil aceptarle hoy como precursor o pionero de la medicina interna. Baroja, en sus memorias (5), sentencia de forma contundente: "De la obra Letamendi-Hipócrates ha quedado poco; yo, para mí, creo que no ha quedado nada. Todo era bluff, retórica y palabrería. Creo que la fama de Letamendi la he comenzado a demoler yo". Conviene recordar, eso sí, que Don Pío fue suspendido por Letamendi, y más de una vez, en la asignatura de Patología General. Baroja, además, reconoció en este profesor su estímulo para el estudio de la filosofía (5).

Por otra parte, la admiración de Menéndez Pelayo o de Galdós por Letamendi (5), e incluso de Ramón y Cajal, quien se refirió a él como "el ingeniosísimo y original doctor Letamendi, el gran 
catalán" (6); o, asimismo, de Pi i Suñer (7), quien lo tachó de "espíritu enorme y genial", contrastan con el juicio histórico de Laín Entralgo sobre su figura: "Letamendi (1828-1897), teórico de la medicina. Con su curso de Patología General, obra compuesta al margen de lo que era la investigación científica del momento, pura especulación de gabinete..." (8).

También en la exposición Los internistas pioneros de la medicina moderna española (Universidad de Alicante, 13-20 de abril de 1994), se mantuvo que "su afición [en alusión a Letamendi] y condiciones para la libre especulación y su amor a la retórica le llevaron a formular una brillante y espectacular doctrina, que el tiempo demostró que no era más que fuegos de artificios sin ninguna base" (profesor Balaguer Perigüel).

Y, por cierto, la ingeniosa frase "el médico que sólo sabe de Medicina, ni Medicina sabe", pertenece al propio Letamendi, y no al doctor Marañón (5).

4. Por último, además del siglo de la tecnificación, nos hallamos en el siglo del envejecimiento (9), con las consiguientes repercusiones para la labor del internista. Y la tecnología médica moderna también ha contribuido, en el nuevo siglo, al olvido de la verdadera práctica clínica, lo que incluye la adecuada exploración física del enfermo, entre otros aspectos.

\section{F. J. Barbado Hernández}

Servicio de Medicina Interna. Hospital Universitario La Paz. Madrid

1. Gómez J. La Medicina Interna: situación actual y nuevos horizontes. Madrid: An Med Interna (Madrid) 2004; 21: 301-305.

2. Ochoa S. Escritos. Madrid: CSIC, 1999. p. 218.

3. Primer Congreso Nacional de Medicina (20-26 de abril de 1919). Programa y conclusiones de los trabajos presentados. Madrid: Imprenta Gráfica Excelsior 1919.

4. Palafox S. Haz y envés del letamendismo neohipocrático. Medicina e Historia, 1965: 9; 3-15.

5. Baroja P. Desde la última vuelta del camino. Planeta, 1970. p. 317-322.

6. Ramón y Cajal S. Charlas de café. Espasa-Calpe, Madrid, 1982:275.

7. Pi i Suñer A. La unidad funcional. Ensayos de Fisiología interorgánica. Minerva, Barcelona, 1918:5-22.

8. Laín Entralgo P. Historia de la Medicina. Barcelona: Salvat 1978: 490499.

9. Barbado Hernández FJ. El siglo del envejecimiento, en El País Semanal, 2003. p. 21-12.

10. Barbado Hernández FJ. Exploración física: ¿venida a menos? Revista Médica 2004; 39: 78. 